\title{
Rapid advances in the timing of the spring passage migration through Israel of the steppe eagle Aquila nipalensis
}

\author{
Piotr Zduniak1 ${ }^{1}$, Reuven Yosef ${ }^{2}$, Tim H. Sparks ${ }^{3}$, Henk Smit ${ }^{2}$, Piotr Tryjanowski ${ }^{3, *}$ \\ ${ }^{1}$ Department of Avian Biology \& Ecology, Faculty of Biology, Adam Mickiewicz University, Umultowska 89, 61-614 Poznań, Poland \\ ${ }^{2}$ International Birding and Research Centre in Eilat, PO Box 774, Eilat 88000, Israel \\ ${ }^{3}$ Institute of Zoology, Poznań University of Life Sciences, Wojska Polskiego 71 C, 60-625 Poznań, Poland
}

\begin{abstract}
We examined phenological change in the spring migratory passage of the predatory steppe eagle Aquila nipalensis from 1977 to 2008. Data were collected at Eilat, Israel, a globally important site for migrating raptors. Changes in the observation dates of spring passage migration were examined using correlation and regression analyses to assess changes over time as well as potential relationships with temperature and with the Indian Ocean Dipole, an index of climate in the wintering area. Over the study period, the number of recorded steppe eagles decreased significantly, as did the proportion of juveniles. Despite the population decrease there was a rapid advance in first spring passage date. Although changes in passage dates were related to environmental conditions in wintering and en-route areas, we suggest that one possible additional reason for such a rapid advance is due to increasing competition between individuals for breeding territories due to dwindling habitats. In addition, changes to some aspects of the passage distribution may be a consequence of a changing age structure.
\end{abstract}

KEY WORDS: Israel · Trends · Passage migration · Population size · Predation · Indian Ocean Dipole Temperature

Resale or republication not permitted without written consent of the publisher

\section{INTRODUCTION}

Phenology - the study of annually recurring lifecycle events, such as the timing of migration-has recently been identified as a particularly sensitive indicator of climate change (Parmesan 2006). There are considerable quantities of information on arrival times of birds in many parts of the world (Lehikoinen et al. 2004). A majority of studies consist of data collected in the breeding grounds and have analysed arrivals in relation to local temperatures (Lehikoinen et al. 2004, Gordo 2007). Some other analyses have suggested that climatic conditions encountered both in the wintering grounds and during migration are important for migratory birds since they determine their physical condition, which results in variable arrival dates and body condition at breeding grounds (Saino et al. 2004, 2007, Mitrus et al. 2005, Gordo 2007).
The International Birding and Research Centre in Eilat, located on the edge of the Negev Desert in Israel, is an especially important hotspot for migratory Palearctic birds where many migration routes converge. In spring, many northbound migrants stop there to rest and feed and a considerable number of migratory raptors can be observed (Yosef 1996, Shirihai et al. 2000). One of the most numerous raptor species passing there is the steppe eagle Aquila nipalensis. The steppe eagle is an abundant migrant in both spring and autumn and an important proportion of the world population of the species passes over Israel (Shirihai et al. 2000). It breeds principally in Asia, from southeast European Russia and perhaps Turkey, east through Central Asia to Manchuria. The steppe eagle is a long-distance migrant, and the west Asian populations move south to winter in the Middle East and southern Africa. Steppe eagles, and many other raptors, have been surveyed at 
Eilat sporadically since 1977 and subsequently each year since 1994, providing an opportunity to study not only changes in raptor population size-as has already been done at bird observatories (Bildstein 2006, Bensusan et al. 2007) - but also changes in phenology, and the relationship between these phenomena.

In the present study we: (1) describe the changes in passage time of the steppe eagle during 1977-2008; (2) examine the potential relationships between passage time and the size of the population; (3) identify relationships between passage time at Eilat and air temperature, both on the migration route and in the wintering area; and (4) examine the relationship between passage time and the Indian Ocean Dipole, used as an index of the climatological situation in Africa.

\section{METHODS}

\subsection{Surveys}

Visual raptor migration surveys have been conducted at Eilat in Israel sporadically since 1977 (for details of method of survey and locations see Shirihai et al. 2000). All soaring birds are counted by deploying volunteers at traditional counting posts across the passage routes taken at this crossroads. During migration, steppe eagles either circulate in thermals or glide, and therefore are easy to detect and count precisely (Spaar \& Bruderer 1996, Shirihai et al. 2000). Distances between observation posts are such that minimal overlap occurs. However, at the end of each day, data between neighbouring positions are compared to check and eliminate possible double counts (details in Shirihai et al. 2000). Ageing of steppe eagles in flight is relatively easy, and birds are classified into 2 categories: 1 to 4 yr olds (hereafter juveniles) 5 yr olds and older (adults) (Yosef \& Fornasari 2004). Recording was sufficiently complete in 13 nonconsecutive years for the quartiles (lower quartile, median, upper quartile) and other percentiles of the spring passage distribution of the steppe eagle to be calculated. In other years data were not recorded throughout the migration period so quartiles could not be calculated. From 1994 to 2008 recording began sufficiently early in the year to be confident that the first passage bird was recorded; earlier in the study period we may have missed the first few passage birds but, because of the large sample sizes involved, we believe that this would make little difference to estimates of quartile dates.

\subsection{Climate data}

As we were unable to precisely define particular wintering grounds or African migration routes of the steppe eagle population (due to lack of ring recoveries from Africa) and match them with finer-scaled climatic variables, we considered the eagle's whole wintering range in eastern and southeastern Africa (Spaar \& Bruderer 1996, Simmons 1997, Meyburg et al. 2003) and a broad migration passage in NE Africa. Temperature data were obtained from the CRUTEM3v data series (www.cru.uea.ac.uk/cru/data/temperature), which provides monthly temperatures as anomalies from a 1961-1990 baseline on a $5^{\circ} \times 5^{\circ}$ grid basis. Values for grid squares between 25 to $40^{\circ} \mathrm{E}$ and $30^{\circ} \mathrm{S}$ to $5^{\circ} \mathrm{N}$ were averaged for each of the calendar months November to February to represent wintering ground temperatures, and values between 30 to $40^{\circ} \mathrm{E}$ and $10^{\circ} \mathrm{S}$ to $30^{\circ} \mathrm{N}$ were averaged for each of the calendar months January to March to represent temperatures for the migration route south of Eilat.

Quite recently it was shown that climate variability in East Africa is linked to the interannual sum of Indian Ocean sea surface temperature (SST) variations, termed the Indian Ocean Dipole (IOD; Marchant et al. 2007). The IOD represents the zonal dipole structure of the various coupled ocean-atmosphere parameters such as SST, surface pressure, outgoing long wave radiation and sea surface height anomalies (Yamagata et al. 2003). This unique ocean-atmosphere coupled phenomenon in the Indian Ocean is characterized by anomalous warming of SST in the western part and anomalous cooling in the eastern part, which is associated with rainfall in eastern and southern Africa (Saji et al. 1999). The intensity of the IOD is thus represented by a SST gradient between the western and the southeastern equatorial Indian Ocean: the Dipole Mode Index (DMI; Saji et al. 1999). When the DMI is positive, increased rainfall and humidity cause vegetation development in tropical eastern Africa (Saji et al. 1999, Marchant et al. 2007).

Steppe eagles arrive at their wintering grounds in eastern and southeastern Africa in November and start to depart in January until February (Simmons 1997, Meyburg et al. 2003). For the analysis of the influence of wintering ground climate on spring passage phenology, we thus used the mean DMI from December to February. DMI data were obtained from the Frontier Research Center for Global Change, Japan (www. jamstec.go.jp/frsgc/research/d1/iod/).

\subsection{Statistical analysis and simulations}

All dates were converted to days of the year (DOY; $1=1$ Jan, etc.) prior to analysis. Because trends through time appeared nonlinear, Spearman's rank correlation was used to assess whether phenology and population series had changed over time. For other 
comparisons, Pearson correlation and regression techniques were employed. Statistical significance was set at $\mathrm{p}<0.05$.

Simulations of the effect of the proportion of juveniles on passage date estimates were based on normal distributions with parameters based on means and standard errors of the lower quartile, median and upper quartile of the juvenile and adult passage distributions. For each quartile, 1000 random numbers from both juvenile and adult distributions were generated and an average date proportional to the percentage of juveniles was calculated. The data are summarised as the 10th to 90th percentiles of these simulations to avoid overlap.

\section{RESULTS}

\subsection{Abundance and age ratio}

During 13 non-consecutive springs, a total of 255356 steppe eagle records were made (mean \pm SE per season $=19643 \pm 5055$, range $=7679$ to 75053 ). The number of birds recorded significantly decreased during the study period (Spearman rank correlation, $\mathrm{r}_{\mathrm{S}}=$ $-0.76, \mathrm{n}=13, \mathrm{p}=0.002$; Fig. 1). Juvenile birds represented $28.4 \%$ of all records, but this figure substantially declined over the years $\left(r_{S}=-0.96, n=13, p<\right.$ 0.001; Fig. 1).

\subsection{Time of spring passage migration}

The records of first birds became significantly earlier during 1994-2008 $\left(\mathrm{r}_{\mathrm{S}}=-0.99, \mathrm{n}=15, \mathrm{p}<0.001\right.$; Fig. 2). A regression of first dates on year suggests that the change in first dates during the period 1994-2008 was

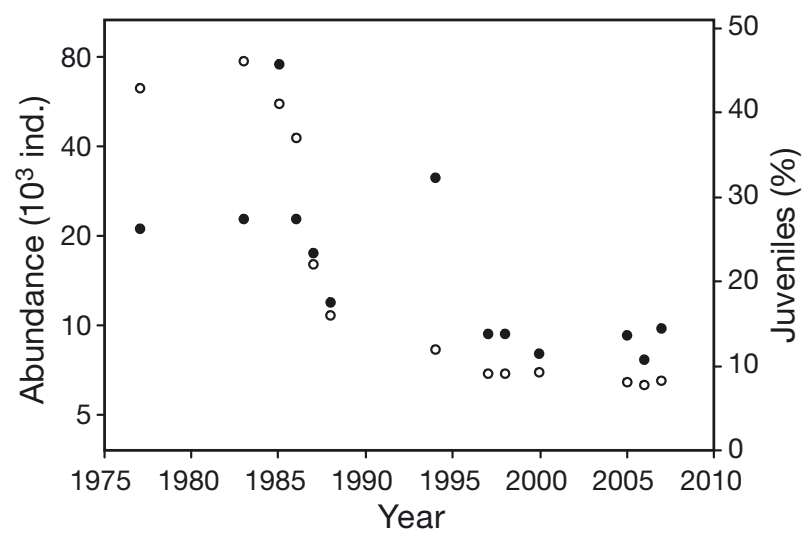

Fig. 1. Aquila nipalensis. Total number of steppe eagles $(\bullet)$ and percentage that were juvenile $(0)$, recorded during 13 non-consecutive spring passages (1977-2008) in Eilat, Israel. Left $y$-axis is log scale

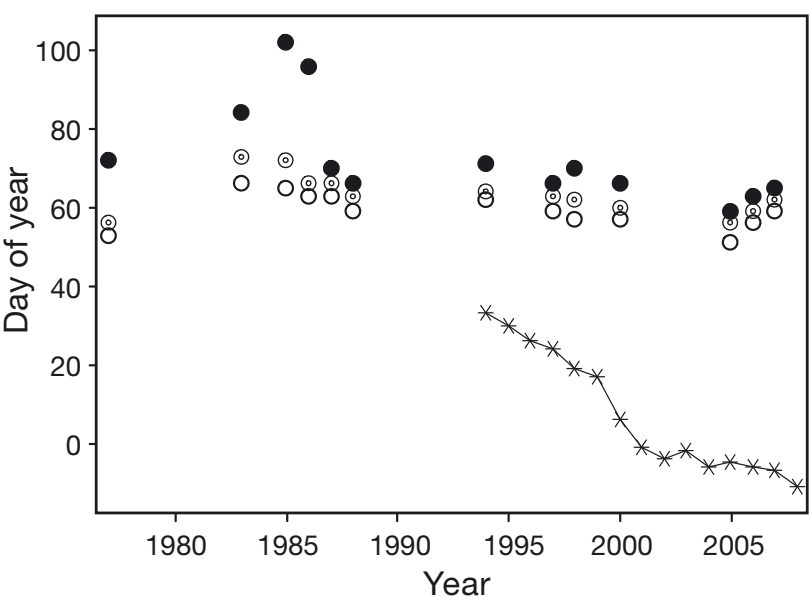

Fig. 2. Aquila nipalensis. Spring passage dates (1977-2008) of steppe eagles at Eilat, Israel. (०) lower quartile; $(\odot)$ median; $(\bullet)$ upper quartile; $(-\mathrm{T}-$ ) first bird

$44 \mathrm{~d}$. Preliminary results suggest that the first bird in 2009 (DOY 19, i.e. 12 Dec) was earlier than in any of the preceding $15 \mathrm{yr}$. The quartile passage dates recorded in a set of 13 non-consecutive years between 1977 and 2008 were significantly earlier in the upper quartile only (lower quartile $\mathrm{r}_{\mathrm{S}}=-0.52, \mathrm{p}=0.068$; median $r_{S}=-0.54, p=0.058$; upper quartile $r_{S}=-0.86$, $\mathrm{p}<0.001$, all $\mathrm{n}=13$; Fig. 2).

\subsection{Relationship between passage migration dates and population size}

The dates of the quartile measures of passage were all positively correlated with population size (Pearson correlation, lower quartile $\mathrm{r}=0.56, \mathrm{p}=0.048$; median $\mathrm{r}=0.62, \mathrm{p}=0.022$, upper quartile $\mathrm{r}=0.80, \mathrm{p}=0.001$, all $n=13$ ). As there were only 7 common years with data on both population size and first passage date, no comparison was made between these 2 variables. Fig. 3 shows that the passage time of juvenile birds was later than that of adult birds (the median juvenile approximately $19 \mathrm{~d}$ later than the median adult). Consequently, a reduced proportion of juvenile birds (see Fig. 1) might be expected to result in an earlier passage date of the whole population. Regressions of quartile passage dates on the percentage of juveniles and year revealed all year trends to be nonsignificant (all p > 0.47) after fitting the percentage of juveniles. Fig. 4 shows the simulation of the effects of a decreasing proportion of juveniles on the quartiles of the passage distribution, based on the data presented in Fig. 3: All quartiles exhibit earlier passage dates, but the effect is most marked for the upper quartile. 


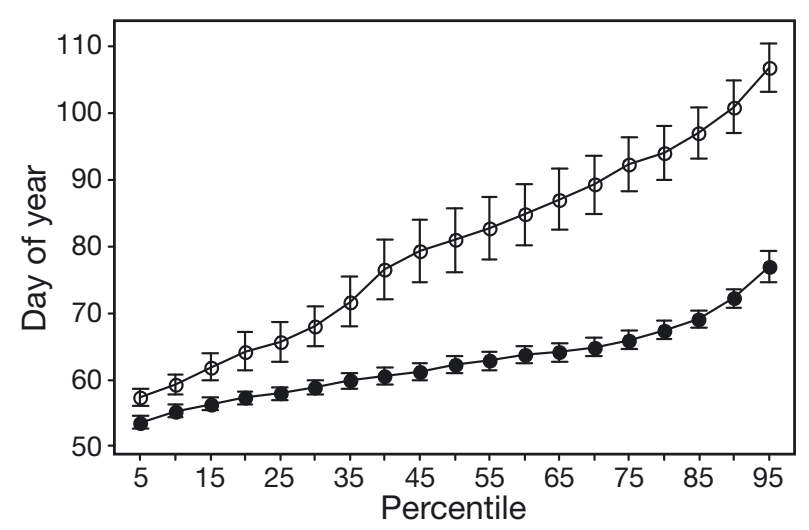

Fig. 3. Aquila nipalensis. Distribution of spring passage timing of adult $(\bullet)$ and juvenile (O) steppe eagles at Eilat, Israel. Data are mean \pm SE from 13 non-consecutive years (1977-2008)

\subsection{Relationship between passage migration dates and climatic factors}

Monthly temperatures on the wintering grounds between November and February increased significantly (correlation with year, all $\mathrm{p}<0.02$ ), but those on the migration route between January and March did not (all $\mathrm{p}>0.14$ ). There was no significant change in December-February IOD $(p=0.85)$. There were significant correlations between November and December temperatures at the wintering grounds and quartile measures of passage (Table 1). December to February wintering temperatures hovered on either side of statistical significance with the first passage date, although February is likely too late to be influential on first passage birds. Migration route temperatures in February were significantly correlated with lower quartile and median passage date (Table 1). Again, the influence of March migration route temperature and first passage bird is unlikely to be valid.

No significant correlations were detected between passage phenology (all $\mathrm{p}>$ 0.27 ) or population measures (total numbers, \% juvenile, both $p>0.23$ ) and December-February IOD.

\section{DISCUSSION}

There are several possible factors that can influence the population fluctuations, or general decline, reported for Eilat. These have been discussed by Yosef \& Fornasari (2004), who linked these changes to the Chernobyl disaster in 1986. The total population of steppe eagles appears to have halved and the proportion of juvenile

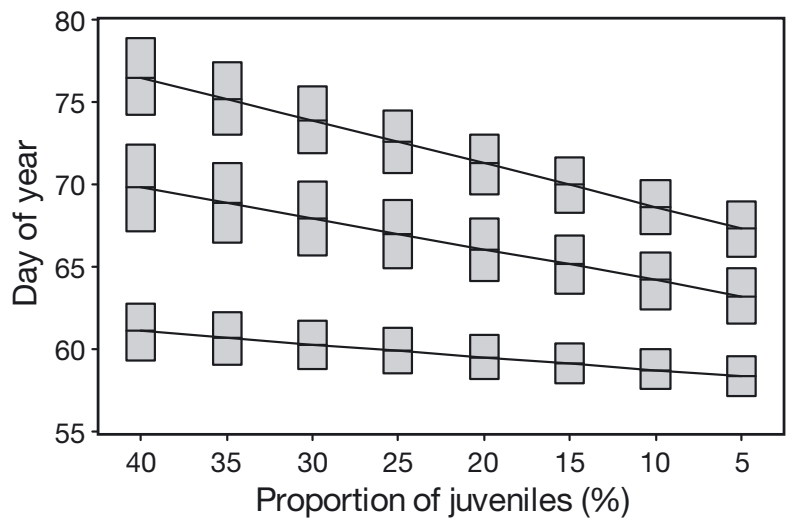

Fig. 4. Aquila nipalensis. Simulation of the effect of a decreasing proportion of juvenile steppe eagles on the lower quartile (lower), median (centre) and upper quartile (upper) passage dates. Boxes show 10th to 90th percentiles from simulation of data summarized in Fig. 3 ; lines connect median values

birds has decreased from ca. $40 \%$ to stabilize at just under $10 \%$. Contrary to expectations for a declining population (see Tryjanowski et al. 2005), there has been an advance in passage migration of first birds, with evidence of advance in quartiles of the passage, particularly the upper quartile. However, adult and juvenile birds migrate at different times and the decline in the proportion of juveniles would be expected to have the effect of appearing to advance the migration, particularly the upper tail. Thus we have 2 processes running counter to expectations. Firstly, the first passage bird has advanced in a declining population. We believe this is because steppe eagles are large soaring birds and therefore the influence of population size on their detection is likely to be much smaller than, for example, a small passerine. Secondly, the percentiles of the distribution, normally expected to be unaffected by changes in population

Table 1. Aquila nipalensis. Correlations (with p-values below) between passage dates and November-February temperatures in wintering grounds, and January-March temperatures on the migration route of steppe eagles through Eilat, Israel. Bold: significant. Please note that with such a large number of comparisons, some significant correlations may arise by chance

\begin{tabular}{|lrrrrrrrr|}
\hline & \multicolumn{3}{c}{ Wintering grounds } & \multicolumn{3}{c|}{ Migration route } \\
& Nov & Dec & Jan & \multicolumn{2}{c}{ Feb } & \multicolumn{2}{c}{ Jan } & \multicolumn{2}{c}{ Feb } & Mar \\
\hline First bird & -0.430 & -0.486 & -0.500 & $\mathbf{- 0 . 5 2 0}$ & 0.320 & -0.314 & $\mathbf{- 0 . 6 5 8}$ \\
& 0.109 & 0.066 & 0.058 & $\mathbf{0 . 0 4 7}$ & 0.245 & 0.254 & $\mathbf{0 . 0 0 8}$ \\
Lower quartile & $\mathbf{- 0 . 8 1 7}$ & $\mathbf{- 0 . 5 8 7}$ & -0.125 & -0.441 & -0.040 & $\mathbf{- 0 . 6 7 7}$ & -0.109 \\
& $\mathbf{0 . 0 0 1}$ & $\mathbf{0 . 0 3 5}$ & 0.684 & 0.131 & 0.898 & $\mathbf{0 . 0 1 1}$ & 0.722 \\
Median & $\mathbf{0 . 8 0 3}$ & $\mathbf{- 0 . 5 5 5}$ & 0.078 & -0.329 & -0.124 & $\mathbf{- 0 . 7 2 7}$ & -0.083 \\
& $\mathbf{0 . 0 0 1}$ & $\mathbf{0 . 0 4 9}$ & 0.800 & 0.272 & 0.687 & $\mathbf{0 . 0 0 5}$ & 0.787 \\
Upper quartile & $\mathbf{- 0 . 7 9 0}$ & $\mathbf{- 0 . 7 6 2}$ & -0.165 & -0.543 & 0.062 & -0.354 & 0.242 \\
& $\mathbf{0 . 0 0 1}$ & $\mathbf{0 . 0 0 2}$ & 0.590 & 0.055 & 0.841 & 0.235 & 0.426 \\
\hline
\end{tabular}


size, do appear to be so affected, particularly by the decline in the proportion of juvenile birds. In a species such as the steppe eagle, where sexual maturity is achieved after several years (in contrast to passerines), the differential passage of the breeding and nonbreeding portions of the population can influence the whole distribution if the balance, as here, is upset. For our study species the effect seems to be most marked in the upper quartile, the measure in which the change in passage time was more significant.

Aspects of spring passage appeared to be influenced by temperatures on the wintering ground and on the migration route. However, since we are dealing with a modest number of years of data and limited knowledge of wintering grounds and migration routes, we should perhaps treat these results with some caution until data from additional years are gathered.

The changes in phenology we observed in the steppe eagle follow changes in very early passerines (Yosef \& Markovets 2009), which may be an important part of the diet of migrating eagles (Yosef 1996). However, we do not believe that lack of food during migration could be so strong a driver to advance the date of migration so much (44 d over $15 \mathrm{yr}$ for the first passage bird). It may be that some changes in Africa produce this pattern; changes related not only directly to climate, but indirectly to food sources. For example, locusts Schistocerca gregaria (Vallebona et al. 2008) are related to climate in Africa and are a food component of eagles during migration (Shirihai et al. 2000). However, if the negative correlations with temperature in the wintering ground are strong, then why are other tropical migrants not advancing as rapidly?

The finding that changed quartile passage dates may just be a consequence of an altered age structure has important implications for the interpretation of the results of other studies. If other species are similarly affected, i.e. by a reduction in the proportion of the non-breeding population, then changes in phenology may be a consequence of the change in the population structure. This is in contrast to results reported by Møller et al. (2008) and predictions by Tryjanowski et al. (2005), who found non-advancing species in decline. Our seemingly counterintuitive result may be a consequence of strong competition in the breeding grounds for breeding sites, because numbers of good territories and/or nests are strongly limited. However, this speculation must remain unanswered because we do not have any detailed data on the breeding ecology of this species and its current situation in the breeding grounds. We believe that, in our particular study system, the first birds are likely to be adults and the first of the breeding population. The earliest birds are generally more productive, and advances in the timing of first birds may be more important to the population than, for example, the timing of later portions of the population (e.g. Tryjanowski \& Sparks 2008). In secretive species, the detection of the first bird may be affected by population decline, but that is hardly the case with steppe eagles at Eilat. The influence of a changing age structure on passage distribution appears potentially capable of further complicating our knowledge of bird migration phenology. We therefore recommend examination of those data sets, typically from bird observatories, where the effect of age structure on passage and arrival timing can be disentangled.

Acknowledgements. We extend our gratitude to many birdwatchers for their help with fieldwork. We dedicate this study to all of those who have devoted their time and effort in watching eagles at Eilat over the past 3 decades. We also thank 3 anonymous referees for constructive comments on the manuscript.

\section{LITERATURE CITED}

Bensusan KJ, Garcia EFJ, Cortes JE (2007) Trends in abundance of migrating raptors at Gibraltar in spring. Ardea 95:83-90

Bildstein KL (2006) Migrating raptors of the world: their ecology and conservation. Cornell University Press, Ithaca, NY

Gordo O (2007) Why are bird-migration dates shifting? A review of weather and climate effects on avian migratory phenology. Clim Res 35:37-58

- Lehikoinen E, Sparks TH, Zalakevicius M (2004) Arrival and departure dates. Adv Ecol Res 35:1-31

Marchant R, Mumbi C, Behera S, Yamagata T (2007) The Indian Ocean dipole - the unsung driver of climatic variability in East Africa. Afr J Ecol 45:4-16

Meyburg BU, Paillat P, Meyburg C (2003) Migration routes of steppe eagles between Asia and Africa: a study by means of satellite telemetry. Condor 105:219-227

Mitrus C, Sparks T, Tryjanowski P (2005) First evidence of phenological change in a transcontinental migrant overwintering in the Indian sub-continent: the red-breasted flycatcher Ficedula parva. Ornis Fenn 82:13-19

> Møller AP, Rubolini D, Lehikoinen E (2008) Populations of migratory bird species that did not show a phenological response to climate change are declining. Proc Natl Acad Sci USA 105:16195-16200

Parmesan C (2006) Ecological and evolutionary responses to recent climate change. Annu Rev Ecol Evol Syst 37: $637-669$

Saino N, Szép T, Romano M, Rubolini D, Spina F, Møller AP (2004) Ecological conditions during winter predict arrival date at the breeding quarters in a trans-Saharan migratory bird. Ecol Lett 7:21-25

Saino N, Rubolini D, Jonzén N, Ergon T, Montemaggiori A, Stenseth NC, Spina F (2007) Temperature and rainfall anomalies in Africa predict timing of spring migration in trans-Saharan migratory birds. Clim Res 35:123-134

Saji NH, Goswami BN, Vinayachandran PN, Yamagata T (1999) A dipole mode in the tropical Indian Ocean. Nature 401:360-363

Shirihai H, Yosef R, Alon D, Kirwan GM, Spaar R (2000) Raptor migration in Israel and the Middle East-a sum- 
mary of 30 years of field research. International Birding and Research Centre in Eilat, Eilat

Simmons RE (1997) Steppe eagle. In: Harrison JA, Allan DG, Underhill LG, Herremans M, Tree AJ, Parker V, Brown CJ (eds) The atlas of southern African birds, Vol. 1: nonpasserines. Birdlife South Africa, Johannesburg

Spaar R, Bruderer B (1996) Soaring migration of steppe eagles Aquila nipalensis in southern Israel: flight behaviour under various wind and thermal conditions. J Avian Biol 27:289-301

Tryjanowski P, Sparks TH (2008) The relationships between phenological traits and brood size of the white stork Ciconia ciconia in western Poland. Acta Oecol 33:203-206

Tryjanowski P, Kuźniak S, Sparks T (2005) What affects the magnitude of change in first arrival dates of migrant birds? J Ornithol 146:200-205

Editorial responsibility: Nils Chr. Stenseth, Oslo, Norway
Vallebona C, Genesio L, Crisci A, Pasqui M, Di Vecchia A, Maracchi G (2008) Large-scale climatic patterns forcing desert locust upsurges in West Africa. Clim Res 37:35-41

Yamagata T, Behera SK, Rao SA, Guan Z, Ashok K, Saji HN (2003) Comments on 'Dipoles, temperature gradient, and tropical climate anomalies'. Bull Am Meteorol Soc 84: 1418-1422

Yosef R (1996) Raptors feeding on migration at Eilat, Israel: Opportunistic behavior or migratory strategy? J Raptor Res 30:242-246

Yosef R, Fornasari L (2004) Simultaneous decline in steppe eagle (Aquila nipalensis) populations and Levant sparrowhawk (Accipiter brevipes) reproductive success: Coincidence or a Chernobyl legacy? Ostrich 75:20-24

Yosef R, Markovets M (2009) Spring bird migration phenology in Eilat, Israel. ZooKeys 31:193-210

Submitted: February 9, 2010; Accepted: July 2, 2010

Proofs received from author(s): August 9, 2010 